\title{
KINERJA PELAYANAN BIDANG REHABILITAS SOSIAL DINAS SOSIAL KOTA PALANGKA RAYA (STUDI KASUS PENGEMIS)
}

\author{
Service Performance in the Social Rehabilitation Sector of the Palangka Raya City Social Service \\ (Case Study of Beggars)
}

\section{Reza Pahlawan* \\ Kristian Lutpian Prasetiawan}

Universitas Muhammadiyah

Palangkaraya, Palangka Raya, Central

Kalimantan, Indonesia

email:

reza.pahlawan@umpalangkaraya.ac.id

\begin{abstract}
Abstrak
Penelitian ini bertujuan untuk menggambarkan dan mendiskripsikan Kinerja Pelayanan Bidang Rehabilitas Sosial Dinas Sosial Kota Palangka Raya (studi kasus Pengemis). Metode penelitian yang digunakan adalah deskriftip kualitatif yaitu dimana peneliti ingin menggambarkan dan mendiskripsikan Kinerja Pelayanan Bidang Rehabilitas Sosial Dinas Sosial Kota Palangka Raya (studi kasus Pengemis). Sumber data yaitu dalam penelitian ini adalah data primer dan data sekunder yang menjadi sumber data primer adalah Sub Bagian Umum dan Kepegawaian, SUB Bidang Pelayanan Rehabilitas Sosial. Tehnik pengumpulan data dalam penelitian ini yaitu Observasi, Wawancara, dan Dokumentasi.

Berdasarkan Hasil Penelitan bahwa Kinerja Pelayanan Bidang Rehabilitas Sosial Dinas Sosial Kota Palangka Raya (Studi Kasus Pengemis) belum cukup baik karena terlihat dari tidak adanya data yang konkrit antara jumlah pengemis yang masuk dan keluar setiap hari/bulannya, minimnya dana pemerintah untuk menangani pengemis tersebut dan minimnya sarana prasarana yang mendukung program pembinaan dan pelayanan rehabilitas pengemis seperti tidak tersedianya rumah singgah untuk para pengemis di rehabilitas, itu yang membuat masih banyaknya terdapat pengemis.
\end{abstract}

\begin{abstract}
This study aims to describe and describe the Service Performance of the Social Rehabilitation Sector of the City of Palangka Raya Social Service (a case study of Beggars). The research method used is a qualitative description which is where the researcher wants to describe and describe the Service Performance of the Social Rehabilitation Sector of the City of Palangka Raya Social Service (a case study of Beggars). Sources of data namely in this study are primary data and secondary data which is the primary data source is the General and Personnel Subdivision, SUB Division of Social Rehabilitation Services. Data collection techniques in this study are Observation, Interview, and Documentation.

Based on the research results that the Service Performance of the Social Rehabilitation Sector of the City of Palangka Raya Social Service (Case Study of Beggars) is not good enough because it can be seen from the absence of concrete data between the number of beggars who enter and leave every day/month, lack of government funds to handle these beggars the lack of infrastructure that supports beggar rehabilitation and service programs such as the unavailability of shelters for beggars in rehabilitation, which makes many beggars still exist.
\end{abstract}

\section{PENDAHULUAN}

Pengemis perkotaan menjadi fenomena yang mulai dipandang sebagai masalah serius, terutama dengan semakin banyaknya permasalahan sosial ekonomi dan politik yang ditimbulkannya. Modernisasi dan industrialisasi sering kali dituding sebagai pemicu, diantara beberapa pemicu yang lain, perkembangan daerah perkotaan secara pesat mengundang terjadinya urbanisasi dan kemudian komunitas-komunitas kumuh atau daerah kumuh yang identik dengan kemiskinan perkotaan.

Salah satu perkotaan yang diminati oleh orang-orang desa untuk didatangi yaitu Kota Palangka Raya. Karena Kota Palangka Raya adalah salah satu kota yang bisa menjanjikan suatu pekerjaan yang layak karena orangorang Palangka Raya mempunyai tingkat keramahan yang cukup tinggi serta di Kota Palangka Raya pun terdapat tempat-tempat wisata, perkantoran, 
dan gedung-gedung yang bisa menawarkan pekerjaan yang layak.

Kemudian dengan adanya krisis berkepanjangan yang tak kunjung menemui jalan terang untuk keluar dari krisis, telah membuat pengemis menjadi salah satu profesi yang paling favorit dijalankan oleh orang-orang yang tidak memiliki pekerjaan tetap, mereka yang tak kunjung mendapat pekerjaan, ataupun mereka yang menjadi korban pemberhentian kerja sepihak karena perusahaan mereka yang tak mampu lagi membiayai gaji pegawai yang terlalu membludak. Bahkan anak-anak mereka pun juga terpaksa harus terseret dalam mata pencaharian ini. Hingga mereka pun menemui jalan buntu untuk terus mencari penghasilan agar mereka dapat terus sekadar dapat menyambung hidup.

Tetapi kenyataannya dengan terlalu banyaknya orangorang daerah yang datang ke Palangka Raya serta susah mendapatkan pekerjaan maka sebagian dari mereka memilih untuk bekerja sebagai pengemis karena pekerjaan ini sangat mudah dan bisa mendapatkan uang untuk kehidupan sehari-hari mereka. Hal ini bahkan dijadikan mereka sebagai “profesi”. Tindakan memintaminta dijalan bila dilakukan secara berulang-ulang dan terus-menerus dilakukan, maka dapat dikatakan bahwa tindakan memintaminta sebagai sebuah pekerjaan.

Permasalahan ini menimbulkan fenomena baru yang perlu penanganan serius dari Dinas sosial dan Pemerintah Kota Palangka Raya, banyak tanggapan yang muncul dari beberapa kalangan masyarakat, ada yang peduli, tapi tidak sedikit masyarakat yang kurang simpatik dengan keberadaan gelandangan dan pengemis yang sering muncul dijalanan.

Menurut Keban (Pasolong, 2008:176) mengatakan kinerja adalah merupakan tingkat pencapaian tujuan. Menurut Widodo (Pasolong, 2008:175) mengatakan bahwa kinerja adalah melakukan suatu kegiatan dan menyempurnakannya sesuai dengan tanggung jawabnya dengan hasil seperti yang diharapkan. Menurut Bernardian dkk (Sedarmayanti, 2007:260) performance is defined as the record of outcomes produced on a specific job function or activity during a specific time period (Kinerja adalah catatan mengenai outcome yang dihasilkan dari suatu aktivitas tertentu, selama kurun waktu tertentu pula).

Menurut Dwiyanto (Pasolong, 2013:203) menjelaskan beberapa indikator yang digunakan untuk mengukur kinerja birokrasi publik, yaitu:

I. Produktivitas, yaitu tidak hanya mengukur tingkat efisiensi, tetapi juga mengukur efektivitas pelayanan. Produktivitas pada umumnya dipahami sebagai ratio antara masuka(input) dengan keluaran(output).

2. Kualitas Pelayanan, yaitu: cenderung menjadi penting dalam menjelaskan kinerja organisasi pelayanan publik. Banyak pandangan negatif yang terbentuk mengenai organisasi publik muncul karena ketidakpuasan publik terhadap kualitas.

3. Responsivitas,yaitu kemampuan birokrasi untuk mengenali kebutuhan masyarakat, menyusun agenda dan prioritas pelayanan, dan mengembangkan program-program pelayanan publik sesuai dengan kebutuhan masyarakat dan aspirasi masyarakat.

4. Responsibilitas, yaitu menjelaskan apakah pelaksanaan kegiatan birokrasi publik itu dilakukan sesuai dengan prinsip-prinsip administrasi yang benar dengan kebijakan birokrasi.

5. Akuntabilitas, yaitu menunjukan pada seberapa besar kebijakan dan kegiatan birokrasi publik tunduk pada para pejabat politik yang dipilih oleh rakyat. Asumsinya ialah bahwa para pejabat politik tersebut karena dipilih rakyat, dengan sendirinya akan selalu memprioritaskan kepentingan publik.

\section{METODOLOGI}

Jenis Penelitian yang penulis pilih adalah penelitian kualitatif. Penelitian dengan menggunakan metode kualitatif dimaksudnkan untuk memahami suatu 
keadaan tentang apa yang terjadi dengan cara deskriftif yaitu dengan menggambarkan keadaan secara sistematis. Yang merujuk pada pendapat yang dikemukakann oleh Menurut Sugiyono (2016:9) metode penelitian kualitatif adalah metode penelitian yang berlandaskan pada filasfat postpositivisme, digunakan untuk meneliti pada kondisi obyek yang alamiah, (sebagai lawannya adalah eksperimen) dimana peneliti adalah sebagai instrument kunci, teknik pengumpulan data dilakukan secara tringulasi (gabungan) analisis data bersifat induktif/kualitatif dan hasil penelitian kualitatif lebih menekan makna dari pada generalisasi.

\section{HASIL DAN PEMBAHASAN}

Berdasarkan hasil penelitian tentang Kinerja Pegawai Dinas Sosial Kota Palangka Raya studi kasus pengemis maka dapat dijelaskan sebagai berikut :

I. Produktivitas

Konsep produktivitas pada umumnya dipahami sebagai rasio antara input dan output, artinya sejauh mana upaya yang dilakukan dengan hasil yang diperoleh dalam periode tertentu. Dalam penelitian ini konsep produktivitas ditekankan pada berapa banyak jumlah pengemis yang masuk setiap bulannya, seberapa banyak pegawai yang aktif bertugas dalam menangani rehabilitas pengemis, serta permasalahan apa yang sering terjadi dan seberapa cepat dapat diselesaikan oleh petugas.

Berdasarkan hasil pengamatan dan wawancara kepada berbagai kalangan pegawai maupun masyarakat yang ada disekitar Dinas Sosial Kota Palangka Raya maka penulis merasa ada beberapa hal yang diperhatikan terkait kinerja pelayanan bidang rehabilitas sosial di Dinas Sosial Kota Palangka Raya (studi kasus pengemis), khususnya dalam aspek produktivitas.
Berdasarkan data yang diperoleh , jumlah pengemis adalah kisaran II 3 Orang.

Dari data di atas dapat diketahui bahwa jumlah pengemis adalah berkisar 113 orang. Namun data pengemis yang masuk ke Dinas Sosial Kota Palangka Raya setiap bulannya tidak di ketahui jumlahnya, dikarenakan tidak ada data kongkrit yang menunjukkan keterangan keluar dan masuknya pengemis. Dalam menjalankan tugas dan fungsinya, pegawai dinas sosial selalu aktif dalam bertugas melayani serta memberikan pembinaan kepada pengemis walaupun jumlah yang diketahui sebanyak 10 orang yang aktif bertugas di lapangan. Berkaitan dengan efektifitas maka perbandingan jumlah pegawai sebanyak 37 orang yang memberikan pelayanan kepada pengemis sebanyak I 27 adalah I : 3. Sehingga dapat dikatakan bahwa seorang pegawai harus menguasai 3 orang pengemis, dan ini cukup efektif. permasalahan yang sering terjadi biasanya adalah pada saat dilakukan pengawasan atau melakukan razia, mereka yang biasanya berkeliaran malah tidak terlihat pada saat dilakukan razia, selain itu permasalah yang ada adalah kurangnya tempat penampungan sementara /rumah singgah sehingga ketika menertibkan pengemisnya tidak adanya penampungan sementara atau rumah singgah.

2. Kualitas Pelayanan

Kualitas pelayanan yaitu meningkatkan kualitas pelayanan publik. Dengan demikian kepuasan pengemis dapat dijadikan indikator kinerja birokrasi publik. Berdasarkan hasil penelitian dapat diketahui bahwa sarana dan prasarana yang ada di Dinas Sosial Kota Palangka Raya belum memadai dalam kegiatan membina mengawasi serta memberikan keterampilan kepada pengemis. Contoh nya alat untuk bengkel kerja yang ada masih belum lengkap, mesin jahit yang sebagiannya sudah mulai rusak. 
Dalam proses pengawasan, jika pegawai tidak jeli dalam memperhatikan setiap kegiatan yang dilakukan pengemis dapat mengambil peluang untuk melakukan tindakan seperti mengambil barang di bemgkel kerja (kunci-kunci, spare part mesin (II). Dinas Sosial Kota Palangka Raya dalam memberikan pelayanan rehabilitas sosial kepada pengemis saat ini memang belum sesuai dengan yang diinginkan oleh pengemis. Hal ini di karenakan jumlah pegawai dinas sosial kota palangka raya terbatas, selain itu sarana dan prasarana untuk kegiatan keterampilan belum lengkap serta sarana dan prasarana untuk rumah singgah belum tersedia.

3. Responsivitas

Responsivitas merupakan kemampuan organisasi untuk mengenali kebutuhan masyarakat, menyusun agenda dan prioritas pelayanan dan mengembangkan program-program pelayanan publik sesuai kebutuhan dan aspirasi masyarakat. Responsivitas dimasukan sebagai salah satu indikator kinerja karena respontivitas mengambarkan kemampuan pegawai Dinas Sosial Kota Palangka Raya dalam melaksanakan kinerjanya untuk mengatasi menanggapi, memenuhi kebutuhan, keluhan terutama tuntutan dari pengemis di Dinas Sosial Kota Palangka Raya.

Responsivitas memerlukan kesiapan sumber daya dari seluruh pegawai yang terkait dalam pelaksanaan pelayanan rehabilitas sosial dan pelayanan kepada pengemis. Dari hasil penelitian yang telah dilakukan, maka penulis merasa ada beberapa hal yang perlu diperhatikan terkait kinerja pelayanan rehabilitas sosial di Dinas Sosial Kota Palangka Raya (Studi Kasus Pengemis). Kemampuan daya tanggap dipengaruhi oleh cepat tidaknya pemberian pelayanan pegawai yang bertugas. Permasalahan yang terjadi pada proses pelayanan rehabiltas bukan hanya pada kinerja pegawai, tetapi juga pada kesiapan pengemis dalam menerima pelayanan rehabilitas, baik pembinaan keterampilan maupun pembinaan moral. Respon Dinas Sosial Kota Palangka Raya dalam menanggapi keluhan dan laporan warga terkait permasalahan banyaknya pengemis maka dinas sosial menampung semua aspirasi dan keluhan sampai dengan memberikan solusi yang sesuai dengan peraturan yang berlaku.

Upaya yang dilakukan dalam menangani pengemis yaitu melakukan razia di setiap tempat yang memang banyak di kunjungi para pengemis, membawa pengemis tersebut untuk selanjutnya diadakan pembinaan, serta setelah pembinaan selesai, para pengemis tersebut di pulangkan ke daerahnya masing-masing.

Kendala yang dihadapi dalam menangani masalah pengemis adalah minimnya dana dari pemerintah sehingga petugas menunggu sampai adanya dana yang cukup, baru melakukan razia, kemudian minimnya sarana dan prasarana dalam melaksanakan rehabilitas.

4. Responsibilitas

Responsibilitas merupakan konsep yang berkenaan dengan standar professional dan kompetensi teknis yang dimiliki oleh birokrasi publik dalam menjalankan tugasnya. Dalam hal ini responsibilitas menekankan kepada kemampuan pegawai Dinas Sosial Kota Palangka Raya dalam melaksanakan program kerja kepada pengemis.

Saat ini pegawai Dinas Sosial Kota Palangka Raya melaksanakan tugas sesuai dengan aturan yang berlaku namun peraturan yang dilanggar oleh pegawai Dinas Sosial Kota Palangka Raya saat melakukan kegiatan pengawasan dan pembinaan kepada pengemis dalam skala kecil masih bisa terjadi oleh sebagian oknum.

Dalam menyelenggarakan kegiatan rehabilitas kendala atau hambatan yang dihadapi oleh dinas sosial adalah minimnya sarana dan prasarana dalam menunjang proses rehabilitas 
sosial khususnya dalam program pembinaan maupun pengawasan, minimnya dana dari pemerintah.

5. Akuntabilitas

Akuntabilitas adalah tingkat kesesuaian dalam memberikan pembinaan dan pengawasan yang dilakukan oleh pegawai Dinas Sosial Kota Palangka Raya pada umumnya telah sesuai dengan ketentuan yang telah ditetapkan dengan mengacu kepada Peraturan Daerah No 09 Tahun 2012. Akuntabilitas merujuk dalam melakukan tanggun jawab, laporan kerja, menjawab atas perilaku/tindakan yang telah dilakukan, serta merupakan bagian dari sanksi dan penghargaan dalam melakukan pembinaan kepada pengemis.

Mewujudkan akuntabilitas merupakan hal yang harus dilakukan oleh Dinas Sosial Kota Palangka Raya demi menciptakan kinerja yang maksimal dan sebagai dasar acuan pengukuran kinerja agar dapat berjalan dengan semestinya. Pertanggung jawaban Dinas Sosial Kota Palangka Raya khususnya bidang pelayanan rehabilitas pengemis Dinas Sosial bertanggung jawab penuh dalam menangani pengemis yakni dengan cara melakukan pembinaan terhadap pengemis yang bertujuan untuk menekan bertumbuh kembangnya pengemis di Kota Palangka Raya. Pegawai dinas sosial mempertanggung jawabkan setiap pelaksanaan tugas kepada masing-masing pegawai yang bersangkutan yang telah diberi SOP (Standar Oprasional Prosedur) dalam melakukan kegiatan sasaran kerja pegawai. Pegawai dinas sosial khususnya bidang pelayanan rehabilitas sosial mempertanggung jawabkan setiap kegiatan yang dilaksanakan dengan memberikan laporan-laporan kegiatan kepada atasan. Pembinaan yang sudah dilakukan oleh Dinas Sosial terhadap pengemis antara lain dengan memberikan pelatihann keterampilan dan di tempatkan di rumah singgah sementara.

\section{KESIMPULAN}

Berdasarkan hasil pembahasan dalam penelitian ini, maka dapat disimpulkan bahwa mengenai kinerja pelayanan bidang rehabilitas sosial di Dinas Sosial Kota Palangka Raya (Studi kasus Pengemis) belum cukup baik karena :

I. Produktivitas

Produktivitas pengawai Dinas Sosial Kota Palangka Raya dalam mengawasi pengemis dapat dikatakan belum berhasil.. Hal ini terlihat dari tidak adanya data yang konkrit antara jumlah pengemis yang masuk dan keluar setiap hari/bulannya .

2. Kualitas Pelayanan

Berdasarkan penelitian dapat diketahui bahwa pelayanan rehabilitas sosial yang diberikan oleh pegawai Dinas Sosial Kota Palangka Raya belum sepenuhnya seesuai kebutuhan dan keinginan pengemis baik berupa jenis ketrampilan yang diberikan, tidak tersedianya rumah singgah serta sarana dan prasarana yang belum memadai dalam kegiatan rehabilitas pengemis. Sejauh ini Dinas Sosial Kota Palangka Raya sudah aktif dalam memberikan informasi, serta pembinaan kepada pengemis walaupun pengemis tidak sepenuhnya berminat dan menerima apa yang di berikan.

3. Responsivitas

Responsivitas pegawaii Dinas Sosial Kota Palangka Raya dalam melakukan pembinaan dan pelayanan rehabilitas pengemis dapat dikatakan cukup baik. Respon Dinas Sosial Kota Palangka Raya dalam menanggapi keluhan dan laporan masyarakat mengenai banyaknya pengemis di Kota Palangka Raya adalah menampung keluhan yang disampaikan oleh masyarakat walaupun solusi yang diberikan tidak pada saat itu, mengingat keluhan-keluhan yang ada bermacam-macam sehingga perlu di diskusikan kembali kepada kepala dinas sosial.

4. Responsibilitas

Responsibilitas pegawai Dinas Sosial Kota Palangka Raya dapat dikatakan belum optimal. Dalam 
menyelenggarakan kegiatan rehabilitas kendala/hambatan yang dihadapi oleh pengawai Dinas Sosial Kota Palangka Raya adalah minimnya dana pemerintah untuk menangani pengemis tersebut dan minimnya sarana prasarana yang mendukung program pembinaan dan pelayanan rehabilitas pengemis seperti tidak tersedianya rumah singgah untuk para pengemis di rehabilitas.

5. Akuntabilitas

Akuntabilitas Pegawai Dinas Sosial Kota Palangka Raya dapat dikatakan cukup baik hal ini di karenakan kesesuaian dalam memberikan pembinaan dan rehabilitas serta pengawasan yang dilakukan pegawai Dinas Sosial Kota Palangka Rayapada umumnya telah sesuai dengan ketentuan yang ditetapkan dengan mengacu kepada peraturan daerah dan perundangan-undangan.

\section{REFERENSI}

Adya,Atya.2004. Dasar-Dasar Pelayanan Prima. Jakarta: PT. Elex Media Komputindo.

Arikunto, Suharsini. 2003. Manajemen Penelitian. Jakarta: PT. Rineka Cipta

Chandra, Gregorius. 2012. Service, Quality \& Satisfaction Edisi 3,Yogyakarta:CV Andi Offset.

Hardiyansyah. 20II. Kualitas Pelayanan Publik. Yogyakarta : Gava Media

Irwan, Juwand. 2004. Kepuasan Pelayanan. Jakarta : Erlangga.

Juniarso Ridwan dan Achmad Sodik Sudrajat. 2010 Hukum Administrasi Negara dan Kebijakan Pelayanan Publik. Bandung: Penerbit Nuansa.

Komarudin. 2014. Reformasi Birokrasi dan Pelayanan Publik. Jakarta : PT. Grasindo
Kuanjojo. 2009. Metode Penelitian. Kediri: Universitas Nusantara PGRI Kediri.

Mahmudi. 20I0. Manajemen Kinerja Sektor Publik, Edisi. kedua. Sekolah Tinggi Ilmu Manajemen YKPN. Yogyakarta.

Pasolong, Harbani. 2013. Kepemimpinan Birokrasi. Bandung : Alfabeta

Sedarmayanti. 2007. Manajemen Sumber Daya Manusia, Reformasi Birokrasi, dan Manajemen Pegawai Negeri Sipil. Bandung : Pt. Reflika Aditama.

Ratminto \& Atik Septi Winarsih. 2007. Manajemen Pelayanan. Yogyakarta: Pustaka Pelajar.

Santosa, Pandji. 2008. Administrasi Publik Teori dan Aplikasi Good Governance. Bandung : Pt. Reflika Aditama.

Setiadi, J. Nugroho. 2003. Konsep dan implementasi dan untuk penelitian pemasaran. Jakarta: Perdana Media.

Silalahi, Ulber. 201I. Asas-Asas Manajemen. Bandung : PT Refika Aditama

Sugiyono. 2014. Metode Penelitian Administrasi. Bandung :Alfabeta

Sugiyono. 2016. Metode Penelitian Kuantitatif, Kualitatif, dan R\&D. Bandung : Alfabeta.

Wibowo. 2013. Manajemen Kinerja. Jakarta: Rajawali Press. 